\title{
Modulation of taste-induced drinking: The effects of concentration shifts and drinking interruptions
}

\author{
DAVID L. RABINER, J. W. KLING, and PATRICIA A. SPRAGUER \\ Brown University, Providence, Rhode Island
}

\begin{abstract}
The drinking of saccharin solutions by nondeprived rats was found to increase on initial exposure as a function of daily sessions and not as a function of previous state of deprivation or vigor of drinking. Large and persisting positive and negative successive contrast effects followed a single shift in concentration. Forcing the drinking to occur in short bouts by withdrawing the drinking tube elevated total intake above the level established by the positive and negative contrasts. The drinking returned to baseline when uninterrupted drinking was permitted. Maximum drinking occurred with 10 - and 20-min interruptions of 2-min drinking periods. Consecutive daily interrupted drinking sessions did not produce further increases in drinking, as might have been predicted by opponent process theory or by a classical conditioning interpretation. It was suggested that the persistence of the positive and negative contrasts was dependent on the limited past experience of the animals with the saccharin taste, and that the enhancement of drinking by interruption may depend on the increased excitement produced by drinking tube withdrawal and the reduction of the excitement by reintroduction of the tube.
\end{abstract}

Taste-induced drinking (TID) is drinking that occurs in the absence of physiological need and is initiated by taste factors. It thus reflects the "pleasures of sensation" (Pfaffmann, 1960) and provides a convenient example of strongly motivated behavior that not only ignores, but may occur in opposition to, physiological regulatory mechanisms (e.g., Rolls, Wood, \& Stevens, 1978).

The fact that many different species, from infancy onward, show vigorous approach to, and consumption of, the same narrow sets of chemical substances suggests the existence of cross-species similarities in peripheral and central neural apparatus (for review, see Pfaffmann, Frank, \& Norgren, 1979). These preferences can be modulated by gut factors (e.g., Cabanac, 1971; Stellar, 1977), which is consistent with the assumption that intake is controlled by a hedonic process (Young, 1976), which in turn is a function of palatability and deprivation (Davis \& Levine, 1977). Therefore, much taste research has sought to specify the adequate stimuli and describe the neural mechanisms that control such taste-driven ingestion.

There are, however, reasons to view TID in a broader context, with a greater emphasis on the experimental influences. Consider the drinking of saccharin solutions by nondeprived rats: (1) The amount consumed in daily drinking tests increases in a negatively accelerated manner for the first 5-10 days (Ernits \& Corbit, 1973), generating what appears to be a typical acquisition curve.

D. L. Rabiner is now at the Department of Psychology, The University of North Carolina at Greensboro, Greensboro, NC 27412-9912. Requests for reprints should be addressed to J. W. Kling, Department of Psychology, Brown University, Providence, RI 02912.
(2) During daily drinks of saccharin, rats apparently acquire a strong craving for the substance; if a period of abstinence is imposed, the consumption on the first reintroduction of saccharin is greatly elevated, showing a "saccharin elation effect" (Gandelman \& Trowill, 1969; Pinel \& Rovner, 1977). (3) Both rats and humans consume more non-nutritive fluids when in the nondeprived state if the flavors and odors are varied (Rolls, Wood, \& Rolls, 1980), suggesting that satiation for specific sensory factors occurs, and is remembered.

Such observations suggest the need for further investigation of nontaste factors in TID behavior. The results reported here demonstrate both short-term and long-term changes in TID as a result of drinking experiences, and they support the hypothesis that repeated exposure to saccharin solutions results, in its absence, in strong cravings for that taste. It is suggested that TID might be an appropriate model for certain cravings or addictions.

\section{GENERAL METHOD}

\section{Subjects}

All rats were specific-pathogen-free males of the Charles River CD strain. They were initially used in operant experiments in which they experienced food and water deprivation. Each animal was allowed at least 4 weeks of ad-lib food and water before the present experiments began. Typically, animals were 150-180 days old and weighed $500-600 \mathrm{~g}$ when entering one of these experiments. They were weighed twice weekly during their stay in the laboratory.

\footnotetext{
Apparatus

In Experiments 1 and 4, animals lived in and were tested in cages that measured $35 \times 35 \times 31.5 \mathrm{~cm}$ and that had solid metal walls, wire mesh tops and bottoms, and transparent Plexiglas doors. In other experiments, the animals lived in these cages but were transported
} 
to a distinctive room in which they were tested in drinking cages having solid walls, wire mesh tops and floors, and sheet aluminum front panels. Each front panel had a single circular opening $2 \mathrm{~cm}$ in diameter centered $2 \mathrm{~cm}$ above the floor. In Experiment 2, these drinking cages measured $14 \mathrm{~cm}$ wide, $20 \mathrm{~cm}$ deep, and $27 \mathrm{~cm}$ high. In Experiments 3 and 5, the size was increased to $21 \mathrm{~cm}$ wide and $30 \mathrm{~cm}$ deep. In all experiments, the animals were fed Charles River RMH 3000 rat diet, and were maintained in temperature- and humidity-controlled rooms. Room lights were on for $14 \mathrm{~h}$ daily; testing occurred near the middle of the light period and at the same time each day. Saccharin solutions were prepared from reagentgrade saccharin sodium and distilled water, and were presented to the animals in 50-ml burettes equipped with stainless steel drinking spouts.

\section{EXPERIMENT 1 ACQUISITION OF SACCHARIN DRINKING}

It has often been observed that acceptance of substances with novel flavors develops over the course of a number of drinking opportunities (e.g., see reviews in Barker, Best, \& Domjan, 1977; Barnett, 1963). With TID of saccharin solutions, daily sessions of 10-60 min typically produce increasing amounts of drinking each day, the volume ingested approaching an asymptote in 5-10 days (e.g., Ernits \& Corbit, 1973). It is not clear whether this saccharin acquisition curve is primarily attributable to the number of distinct sessions or to the cumulative effects of the total volume of solution ingested. To compare these factors, three groups of rats were allowed to drink saccharin for 10 daily 30 -min sessions. Group 1 was given standard, daily nondeprived drinking opportunities. Group 2 was water deprived on the first 2 days (which preliminary experiments indicated would lead rats to drink approximately as much saccharin in 2 days as nondeprived rats would drink in the first 5 days) and were thereafter again on ad-lib water. Group 3 was water deprived for the first 5 days but allowed to drink only as much saccharin per day as the average Group 1 (nondeprived) intake on each of those days. If the cumulative volume ingested determines the saccharin acquisition curve, Group 2 should require fewer daily sessions to arrive at asymptote. However, if number of sessions is important, all groups should require the same number of days to reach asymptote. Because preference for a flavor is increased if it has been consumed under food deprivation (Revusky, 1967), Group 3 is required in the design as a control for possible water-deprivation effects on preference. Water deprivation for Group 3 was extended to 5 days so that the rats would be deprived during the time they were allowed to drink an amount of saccharin solution approximately equal to that drunk by the other two groups.

\section{Method}

Eighteen rats were divided randomly into three groups of 6 . Each rat was housed and tested in one of the transparent-door cages. Rats in the nondeprived group received standard saccharin acquisition training: food and water were available ad lib, except that food was removed 30 min prior to testing and water was absent during testing; .01-M saccharin solution was placed on the cage for $30 \mathrm{~min}$, and food and water were replaced when the saccharin was removed.
The rats in the 2-day group were deprived of water for $22.5 \mathrm{~h}$ prior to saccharin presentation on the first 2 test days; thereafter; they received the same treatment as the nondeprived group. Rats in the 5-day group were water deprived for the first 5 sessions, but each burette was filled with only the average amount drunk by the nondeprived group on the same ordinal day. All rats received exactly the same treatment on Days 6-10: they were tested while nondeprived and were allowed to drink saccharin for $30 \mathrm{~min}$ daily.

\section{Results and Discussion}

Rats in the nondeprived group drank increasing amounts of saccharin over the first 5 days and thereafter maintained approximately constant intakes. This is a typical saccharin acquisition curve (Ernits \& Corbit, 1973). On the average, rats in the 2-day group drank approximately $13 \%$ more saccharin solution $(28.9 \mathrm{ml})$ in their first 2 (deprived) days than the rats in the nondeprived group drank in their first 5 days $(25.4 \mathrm{ml})$. However, when the 2-day rats were switched to nondeprived conditions, they drank approximately the same amounts and took the same number of days to reach asymptote as the nondeprived group rats. The intakes of the 5-day group were restricted to the average intakes of the nondeprived group for the first 5 days; when no longer deprived (Days 6-10), their intakes were very similar to those of the other two groups. These results are shown in Figure 1.

The number of daily sessions thus seems to be a more important determiner of the saccharin acquisition curve than does the total amount of solution ingested. Furthermore, water deprivation and its associated vigorous saccharin drinking does not seem to influence the rate of approach to, or the absolute level of, the nondeprived asymptote. Apparently, the widely spaced opportunities to drink the novel-tasting substance and to experience its consequences (or lack thereof) are the critical aspects. "Learned safety" or similar concepts (see Best \& Barker, 1977; Kalat, 1977) seem applicable, whereas number of drinking responses and/or level of prior fluid deprivation seem to be relatively unimportant.

\section{EXPERIMENT 2 SUCCESSIVE CONTRAST EFFECTS}

TID varies as a function of concentration of saccharin (and other) solutions (Ernits \& Corbit, 1973). Typically, TID research exposes each animal to each concentration. The extent to which such experiences with many different concentrations influence the reactions to each of the solutions must be considerable, judging from the effects of such procedures as observed in other contexts. For example, robust simultaneous and successive negative contrasts appear in sucrose drinking (Flaherty \& Kaplan, 1979) and saccharin drinking (Flaherty \& Rowan, 1986), auditory generalization gradients are sharpened by discrimination training (Jenkins \& Harrison, 1960), and differences in reinforcing effects are more extreme when each animal is exposed to each condition than when a single reinforcement condition is used with each animal (Marx \& Pieper, 1962; Schrier, 1958). Indeed, negative 


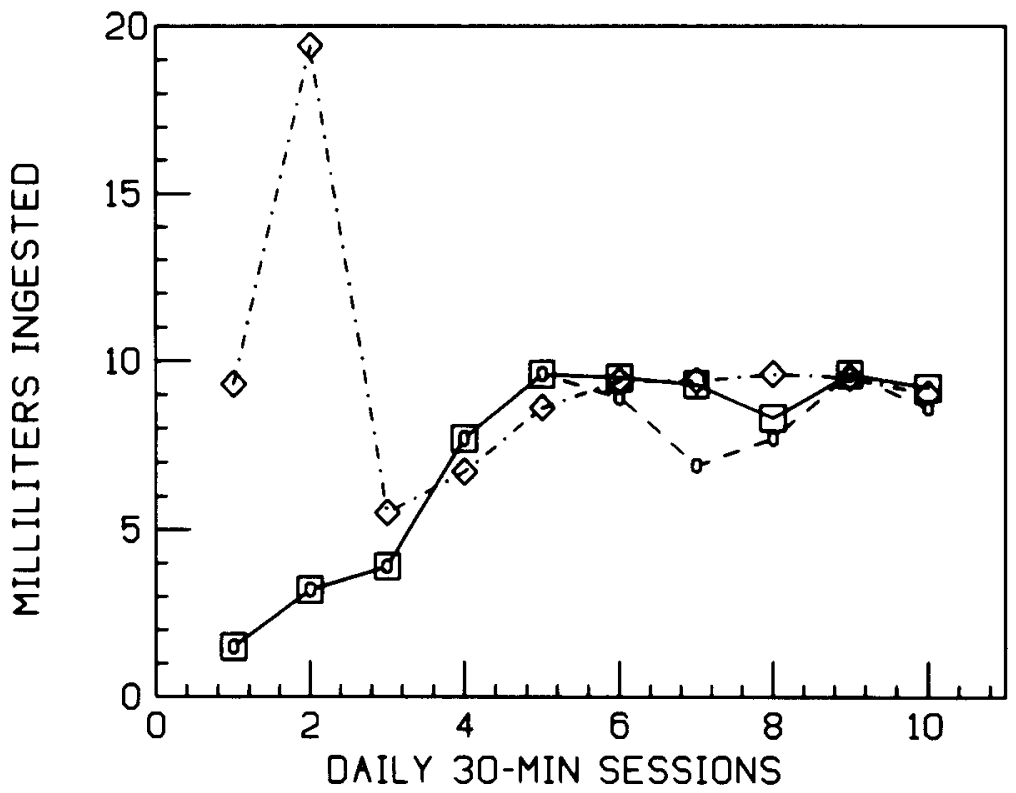

Figure 1. Acquisition of taste-induced saccharin drinking. Mean volume drunk per daily 30-min test. Squares: ad-lib water throughout experiment. Diamonds: water deprived on Days 1 and 2, ad-lib water thereanter. Closed circles: water deprived for 5 days, with intake limited to ad-lib mean, and ad lib on Days 6-10.

reinforcement contrast effects that persist for at least four sessions have been shown to follow a single shift in sucrose concentrations (Riley \& Dunlap, 1979).

It thus seems probable that successive contrast effects would be generated in TID by a single shift in saccharin concentrations. To examine this possibility and to provide baseline data for subsequent experiments, rats were allowed daily drinks of saccharin solutions until stable intakes were observed ( 10 days). Half the rats then were switched to different concentrations, and new intake levels were determined.

\section{Method}

Twenty rats were divided into four groups that were matched for average water intake under ad-lib conditions. Two groups were assigned by chance to the low-concentration $(.0025 \mathrm{M})$ and two were assigned to the high-concentration (.01 $\mathrm{M}$ ) conditions. Rats were run in squads of 4 ( 1 from each group) in test cages located in an adjacent room. In each session, the drinking tube was advanced into the test cage, remained there for $30 \mathrm{~min}$, and was then withdrawn. Animals were then returned to their colony room and home cages, where food and water again were available. On Day 11, two of the groups were switched to the other saccharin concentration. All rats then were tested for an additional 10 days.

\section{Results and Discussion}

Typical saccharin acquisition curves were produced during the preshift period. The high- and low-concentration averages were not reliably different. Such minimal differences with separate groups designs are frequent outcomes in studies of reinforcement and incentive (see, e.g., review in Kling \& Schrier, 1971). In TID, if each rat is given the opportunity to drink several concentrations of saccharin, differences between the intakes of .0025-M and .01-
M solutions might be expected to average $20 \%$ or more (Ernits \& Corbit, 1973). Differences of even greater magnitude appeared when we switched concentrations. The combined mean intake for all rats drinking .01-M saccharin solution on Day 10 was $12.91 \mathrm{ml}$; the mean intake for those shifted on Day 11 to $.0025-\mathrm{M}$ solution was $6.20 \mathrm{ml}$ (an average decrease of 52\%). The comparable figures for preshift drinking of $.0025-\mathrm{M}$ solution on Day 10 and postshift drinking of $.01-\mathrm{M}$ solution on Day 11 were 11.16 and $17.64 \mathrm{ml}$ (an average increase of $58 \%$ ).

Within-subjects comparisons revealed very reliable changes. For animals given the concentration decrease, every rat decreased its intake from Day 10 to Day 11; for those given the concentration increase, every rat increased its intake. The down-shifted rats decreased their intake, on average, $5.12 \mathrm{ml}[t(4)=3.01, .01<p<.025]$. The upward-shifted rats increased their intakes, on average, $6.12 \mathrm{ml}[t(4)=3.87, p<.01]$.

Between-groups comparisons showed similar effects. On the first postshift day (Day 11), the group shifted from low to high drank, on average, $7.14 \mathrm{ml}$ more than the group always given the high concentration $[t(4)=2.16$, $p<.05]$. The group shifted from high to low drank, on average, $4.22 \mathrm{ml}$ less than the group always given the low concentration $[t(4)=2.45, p<.05]$. The changes in concentrations thus produced reliable positive and negative contrast effects. These effects are shown in Figure 2. The groups drinking each concentration were combined for preshift plotting. Note that the group assigned by chance to continue throughout on .01-M solution had a (nonreliably) lower average intake than the group assigned to be shifted downward. This may have made the nega- 


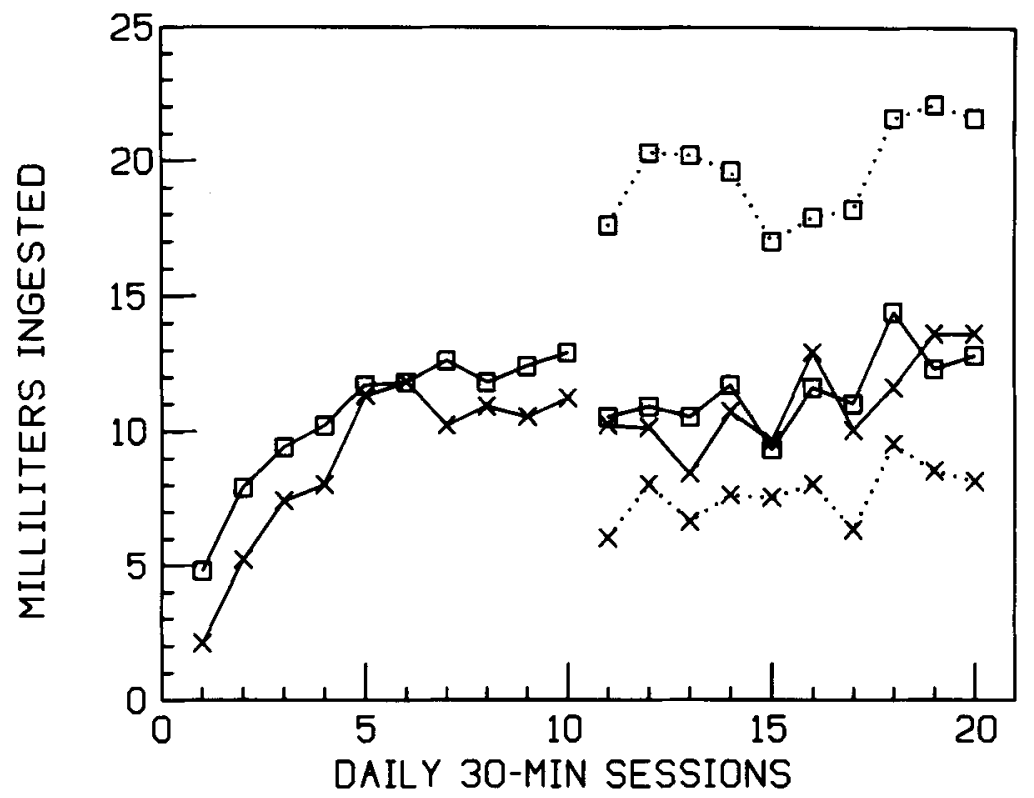

Figure 2. Positive and negative successive contrast effects in saccharin solution drinking. Mean volume drunk per daily 30 -min test. Half of each group was changed to the other concentration on Day 11. Continuous lines: unchanged concentrations. Broken lines: changed concentrations. Squares: .01 M. Xs: .0025 M.

tive contrast effect even smaller than it might have been had the groups been larger or better matched.

These contrast effects under nondeprived conditions are consistent with the observations of positive and negative contrasts observed for saccharin reinforcing effects in runway and in barpressing situations (Weinstein, 1970, 1978), and with the finding of negative contrast in fooddeprived saccharin drinking (Flaherty \& Rowan, 1986). Why saccharin contrast effects have frequently been difficult to demonstrate in successive-sessions procedures (e.g., Vogel, Mikulka, \& Spear, 1968) is not at all clear, since concentration ranges and deprivation conditions seem not to differentiate the successful from the nonsuccessful demonstrations.

The presence of contrast effects demonstrates that TID is strongly influenced by prior experience, the memory for which persists across days. Such effects remind us that TID is unlikely to be a pure measure of taste processes (as suggested by Jacobs \& Sharma, 1969). The contrasts also suggest a convenient means of producing different levels of motivation in nondeprived animals, and perhaps offer a reliable and relatively direct measure of "affective contrast"' (Solomon, 1982).

Many models of motivated behavior assume a negative feedback process in which some state (e.g., hunger, nicotine craving) is responsible for initiating consummatory behavior, with this behavior, in turn, responsible for reducing the underlying state. A model of this general type appears consistent with the facts of well-developed cigarette smoking, where a shift to low-nicotine cigarettes produces more smoking and deeper inhalation (e.g., Jarvik, Popek, Schneider, Baer-Weiss, \& Gritz, 1978; and the review in McMorrow \& Foxx, 1983, especially pp. 316-319). The model seems incompatible with TID of saccharin solutions, where a reduction in concentration produces a reduction in drinking, whereas an increase in concentration produces increased drinking. Although the animals appear to develop a strong craving for the solutions, they do not drink as if counting the number of saccharin molecules ingested. Neither do they drink as if totally controlled by the momentary sensory characteristics, for then the preshift difference between high- and low-concentration groups would be more apparent, and there would be no successive contrast effects. However, the results do seem consistent with the hypothesis that each animal's prior saccharin taste experience establishes in memory some representation of that taste, and that the immediate reaction to any subsequent saccharin taste is influenced by such memory. For animals drinking the $.0025-\mathrm{M}$ saccharin solution, it is the sweetest taste they have ever experienced; but for the animals shifted to the $.0025-\mathrm{M}$ solution after prior experience with the .01-M solution, the $.0025-\mathrm{M}$ solution is much less sweet than that to which they have been accustomed. Comparable, but opposite, effects would presumably occur for rats shifted to a higher concentration than that with which they have been familiarized. Drinking behavior of the shifted rats would be expected to show contrast effects because the vigor of reaction is in part a function of the concentration with which the animal is in contact, and in part a function of the memory of the previous concentration.

Bevan's (1966) interpretation of Helson's (1966) adaptation level theory is consistent with this point of view. Bevan assumed that the effectiveness of a reinforcing stimulus was determined by the sensory properties of that stimulus in relation to the norm established by prior ex- 
perience with that sensory dimension. However, Bevan also assumed that the reinforcing effects would drift toward some average value with long and unaltered use of any specific reinforcer. The contrast effects in the present procedure do not seem to wane over time, at least for the 10 postshift sessions in this experiment and the 19 sessions of Experiment 3 in which these same animals were used.

It is interesting to note that the adaptation level interpretation of successive contrast effects frequently has been called inadequate (see, e.g., Kling \& Schrier, 1971, p. 634; Mackintosh, 1974 , p. 390 ) because it predicts relatively symmetrical positive and negative successive contrasts, and robust positive contrast effects have been difficult to demonstrate (see Flaherty, 1982). The present procedure does produce more or less symmetrical contrast effects, making adaptation level theory once again plausible.

\section{EXPERIMENT 3 INTERRUPTED DRINKING EFFECTS}

One of the characteristics of many strong cravings is that the behavior is phasic: a cigarette is smoked, there is a period of nonsmoking, and then smoking occurs again. Homeostatic, negative feedback models explain the phasic characteristic of the behavior in terms of the cyclic reduction of the instigating state and its recovery of strength over time. A more parsimonious assumption concerning the phasic nature of many cravings would suggest that the behavior stops, not because the signal from some state is removed, but for more trivial reasons. For example, cigarette smoking is limited by the burning time of the cigarette; saccharin drinking is limited by the short-term capacity of the stomach. However, the interruptions forced upon the consummatory behavior by these practical considerations may strengthen the behavior through the additional arousal provided by the interruption itself (Amsel, 1958) and give it the appearance of strongly motivated behavior. For example, there may be increased vigor of responding because the interruptions generate "frustration-produced drive" (Amsel, 1958). Subsequently, the phasic nature of the behavior may provide opportunities for classically conditioning a reaction that has physiological (Siegel, 1979) and affective (Solomon \& Corbit, 1974) characteristics opposite those accompanying the consummatory behavior. Once established, such “opponent processes" (Solomon \& Corbit, 1974) would provide the negative drive states required by homeostatic models, and responses made initially for taste alone (or for peer approval alone) could eventually become necessary to reduce the strong negative states.

To examine the possibility that arbitrarily disrupting TID would increase its occurrence, rats were allowed access to the drinking tubes for 2-min periods, separated by 5 -min periods when the tubes were withdrawn. If such externally imposed phasic conditions contribute to the strength of cravings, the amount drunk should increase when the interrupted drinking procedure is introduced.

\section{Method}

The same four groups of 5 rats each that had been used in the saccharin contrast study (Experiment 2) were used in this experiment. Because some animals had shown very high volumes of drinking, ceiling effects were feared. To reduce total intakes, the testing cages were enlarged by $50 \%$ (to $21 \times 30 \mathrm{~cm}$ ). The change had the desired effect: drinking was reduced by about $15 \%-20 \%$. After 3 daily 30 -min drinking sessions in these new testing cages, the interruption procedure was introduced. Rats were placed in the individual testing cages in squads of 4 , the drinking tubes were automatically advanced into the cages, and $2 \mathrm{~min}$ later they were withdrawn for $5 \mathrm{~min}$. This procedure was repeated, providing $152-\mathrm{min}$ drinking periods and 145 -min periods of enforced nondrinking. At the conclusion of the 15th drinking period, the animals were returned to their home cages in the colony room where food and water again were available ad lib. Additional interrupted drinking sessions were run after $3,3,1$, and 3 intervening uninterrupted drinking days.

\section{Results and Discussion}

On the first 2 interrupted drinking sessions, every rat increased his intake in comparison with the amount he had drunk on the preceding uninterrupted drinking day. On the 3rd interrupted session, 19 of 20 rats increased their intakes, and on the last 2 interrupted drinking sessions, 18 of 20 increased their intakes. For the four groups of 5 rats, within-groups $t$ tests revealed significant increases for every group on every interruption, with two exceptions: on the 3rd interruption session for the group previously switched to the low concentration, and on the 5 th interruption session for the group always drinking the low concentration [all other $t \mathrm{~s}(4)>2.2, p<.05$ ]. The effects of the interruptions are shown in Figure 3.

In general, the four groups maintained their ordinal relationships during interruption tests and interpolated baseline sessions, indicating that the interruption procedure modulates existing levels of consummatory behavior rather than bringing all subjects to some new level of drinking. Note also that the enhanced drinking attributable to interruption exists only for the duration of the session in which the procedure is employed, while the successive contrast effects produced by the single shift in Experiment 2 still are very evident throughout Experiment 3 .

On the 1st interruption test session, the largest absolute increment in drinking was shown by the group previously switched (in Experiment 2) from low to high saccharin concentration (Group L-H), whereas the largest percentage increase in drinking was shown by the group previously switched from high to low concentration (Group H-L). On average, phasic drinking procedures double (approximately) the intake level existing prior to the interruption, with animals generally maintaining their ordinal position in volume consumed. The slopes of the regression lines for the first 2 interrupted drinking sessions (when all rats showed drinking increases) were 1.85 and 2.21. For the 5 interruption sessions, the coefficients of correlation of amount of drinking on the previous baseline day with that on the interruption day were +.90 , $+.96,+.71,+.96$, and +.66 . Correlations may have 


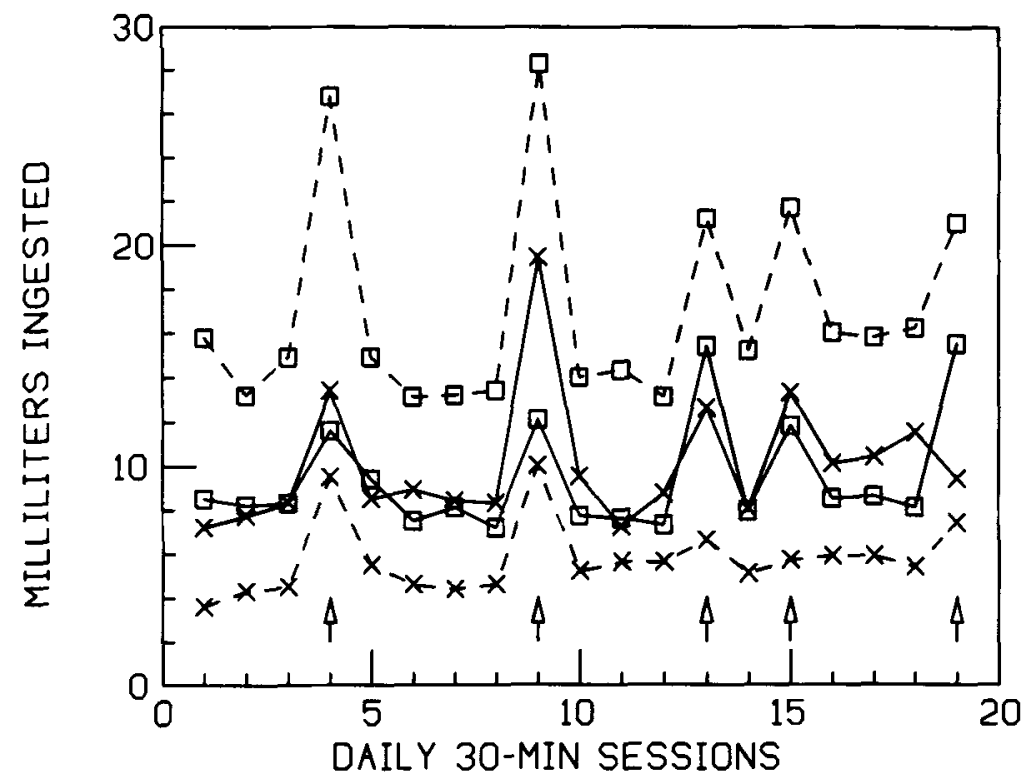

Figure 3. Effects of interrupting drinking sessions. Drinking tubes were withdrawn for 5 min after every 2 min of drinking, on Days 4, 9, 13, 15, and 19. Arrows mark sessions in which drinking was interrupted. Continuous lines: no experience with switch in concentrations. Broken lines: single shift of concentrations in Experiment 2. Squares: $.01 \mathrm{M}$. Xs: .0025 M.

been constrained by ceiling effects on large-volume drinkers, inasmuch as some rats were drinking as much as $40 \mathrm{ml}$ in $30 \mathrm{~min}$, but, generally, the effect of interruption was proportional to the vigor of drinking before interruption.

Both frustration theory (Amsel, 1958) and opponentprocess theory (Solomon \& Corbit, 1974) could account for the increased drinking that results from interruption of the drinking session. Frustration theory would assume that interruption of the strongly motivated consummatory response generates a drive state that adds to the total level of motivation and thus increases the vigor of the preeminent response (in this case, drinking) when it again becomes possible, and that the more vigorous drinkers would have a larger increment to their total drive as a consequence of interruption than would the less vigorous drinkers. The frustration-produced drive is assumed to rise rapidly to maximum strength and then decline (Amsel \& Roussel, 1952), suggesting that it might be maximum early in the interruption interval and start to decline if the drinking tube were withheld for a long period.

Opponent-process theory would assume that a positive hedonic state associated with saccharin drinking would generate a negative hedonic state, that this negative state would be slow to rise and slow to decline, that the negative state would arise during the drinking period and persist into the interruption interval before starting to decline, and that vigorous drinking would occur when the tube was reinserted as a means of reducing the negative state.

Both theories would predict that the amount of drinking would be a nonmonotonic function of the length of interruption. The next experiment examined the consequences of different lengths of interruptions.

\section{EXPERIMENT 4 DURATION OF INTERRUPTION}

As demonstrated in Experiment 3, 5-min interruptions between 2-min drinking periods substantially increased the amount consumed of both low- and high-concentration saccharin solutions. Although the withdrawal and reinsertion of the drinking tube seems to be the cause of the increased drinking, the possibility remains that the mere increase in the total length of the experimental session caused by breaking up the drinking time might allow larger volumes to be ingested. The present experiment examined the effects of varying the length of the periods between the 2-min drinking intervals, and included a control session for the total length of the various experimental periods.

\section{Method}

The 6 rats used as the nondeprived group of Experiment 1 were employed in this experiment. Food and water were available at all times except that food was withdrawn 30 min before the daily session and water was withdrawn just prior to the presentation of the saccharin solution. The rats already had had 10 consecutive daily sessions in which .01-M saccharin solution was presented for $30 \mathrm{~min}$. On the 11th day, the drinking tubes were presented for 2 -min intervals separated by 1 -min periods of unavailability. The total session consisted of 15 opportunities to drink $(=30 \mathrm{~min}$ ) plus 14 -min periods of tube withdrawal. At least 3 baseline days (i.e., 30-min continuous availability of saccharin per day) separated each 
interrupted drinking test, and successive interrupted tests used withdrawal periods of $5,10,20,60,5$, and $5 \mathrm{~min}$. A control session for total experimental time was run 4 days after the second 5-min interruption test day. On the control day, saccharin was constantly available, and readings of intake were taken at the intervals corresponding to the total length of the 1-, 5-, 10-, and 20-min interruption sessions (i.e., $44,100,170$, and $310 \mathrm{~min}$ ).

\section{Results and Discussion}

Every rat drank more on every interruption day than it did on the preceding baseline day. All interruption intervals increased saccharin drinking significantly in comparison with the preceding days' uninterrupted baseline values $(t$ tests for paired measures, one-tailed $p$ values $=$ .01 for the 5-, 10-, and 20-min interruptions, and .02 for the 1 - and 60-min interruptions, $d f=5$ ). The largest increase was produced by the 10 -min interruption (Figure 4). Subsequent retests with the 5-min interruption condition produced essentially the same intakes as the first 5-min session, indicating that the decreased intake on the 60-min test session was not due to a growing aversion to saccharin, or to the aging of the animals.

Even though duration of the interruption interval was confounded with sequence of testing, for purposes of evaluating these exploratory data, an analysis of variance was run on the 1 -min to 60 -min drinking scores: $F(4,20)$ $=6.62, p=.01$, suggesting very strongly that duration of the interruption interval influences the amount ingested. In fact, every rat drank more under the 5-min interruption condition than under the 1-min condition, and every rat drank more under the 10 - and 20 -min conditions than un- der the 1-, 5-, and 60-min conditions. Differences between the 5-min and the 60-min conditions were not statistically significant. Thus, the interruption interval that produces the greatest amount of drinking lies in the $10-$ to 20 -min range.

The exact shape of the intake $x$ interruption curve probably depends upon such variables as the length and the number of drinking periods and the concentration of the solution. Spector and Smith (1984) showed that bouts of sucrose drinking by nondeprived rats decrease in duration and increase in rate of drinking as sucrose concentration is increased from $0.1 \mathrm{M}$ to $1.0 \mathrm{M}$. They suggested that postingestional satiety mechanisms limit the bout length. If the satiety mechanism "counts" calories, it presumably would be insensitive to volume $x$ concentration effects in (noncaloric) saccharin drinking, and a family of curves like those in Figure 3, with concentration as the parameter, would all have the peak at the same interruption interval. If, however, the satiety mechanism is sensitive to taste factors, the maximally effective interruption interval should increase as saccharin concentration is increased.

The fact that the greatest intakes were seen with 10 and 20-min interruptions of drinking seems inconsistent with frustration theory, where the strength of the frustration-produced drive is assumed to rise to its maximum very rapidly and then decline (Amsel \& Roussel, 1952 , p. 366). Indeed, in the classic double-runway situation, with food deprivation and food reinforcement, it was found that the frustration effect had disappeared

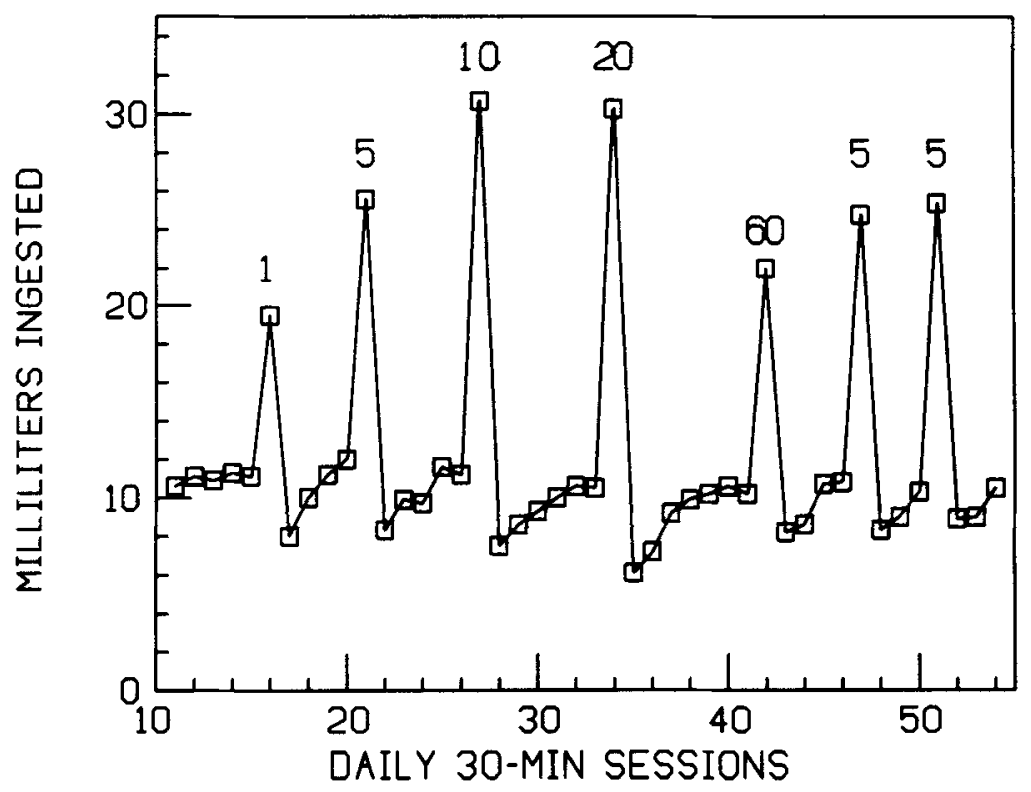

Figure 4. Mean intake of .01-M saccharin solution during daily 30-min drinking sessions. Labels indicate the duration (in minutes) that drinking tubes were withdrawn between 2-min periods of tube insertion. Unlabeled sessions: drinking tubes continuously available for $\mathbf{3 0} \mathrm{min}$. 
within $90 \mathrm{sec}$ (MacKinnon \& Amsel, 1964). Nondeprived, saccharin-reinforced double-runway behavior seems not to have been studied, but the duration of the frustration effect would not be expected to persist longer than that found in the food-deprivation case.

The nonmonotonic function seems to eliminate the possibility that increased drinking under conditions of interruption merely reflects curious exploration of the drinking tube or the place where it appears, or that the effect is attributable to spillage, inasmuch as the number of presentations and withdrawals of the drinking tube was constant over all interruption intervals. However, as a direct check on these possibilities, 5 naive rats, maintained on ad-lib food and water, were given 5 interrupted drinking sessions, each separated by 3 uninterrupted sessions, with the drinking tubes filled with water. No systematic effects of interruption were seen, no rat ever drank more than $1.7 \mathrm{ml}$, many scores of 0 were recorded, and the median intake on interruption days was $0.2 \mathrm{ml}$. Withdrawal and reinsertion of the tube does not induce vigorous drinking in the absence of strong craving for the solution.

Total time from start to finish of a session varied from $30 \mathrm{~min}$ (for the uninterrupted, baseline condition) to $870 \mathrm{~min}$ (for the 60-min interruption condition). The longer sessions might allow greater opportunities for fluid processing and might also produce significantly greater fluid deprivation than the shorter sessions. A continuousaccess session was used to evaluate such factors, with fluid consumption being measured after each interval corresponding to a session with 14 interruptions of $0,1,5$, 10 , and $20 \mathrm{~min}$.

The amounts consumed after various periods, the drinking that occurred during interrupted drinking sessions having equal total session times, and the intakes on continuous-access baseline days immediately preceding each interrupted drinking session are given in Table 1. Note that all interrupted drinking sessions produced more drinking than occurred on the preceding baseline day, and that the periodic withdrawal and reinsertion of the drinking tube produced greater consumption than did the mere passage of time. For example, the rats drank (on average) $19.5 \mathrm{ml}$ when 1-min interruptions separated the 15 2 -min drinking periods (total time $=44 \mathrm{~min}$ ), but they drank only $11.5 \mathrm{ml}$ when given a continuous $44-\mathrm{min}$

Table 1

Interruption Effects on Drinking: Saccharin Acquisition Effect

\begin{tabular}{|c|c|c|c|c|}
\hline \multirow[b]{2}{*}{$\begin{array}{l}\text { Interruption } \\
\text { (in min) }\end{array}$} & \multirow{2}{*}{$\begin{array}{l}\text { Session } \\
\text { Length } \\
\text { (in min) }\end{array}$} & \multicolumn{3}{|c|}{ Mean Intake (in ml) } \\
\hline & & $\begin{array}{c}\text { Previous } \\
\text { Day }\end{array}$ & $\begin{array}{c}\text { Interruption } \\
\text { Day }\end{array}$ & $\begin{array}{c}\text { Continuous } \\
\text { Day }\end{array}$ \\
\hline 1 & 44 & 10.6 & $19.5^{*}$ & $11.5^{*}$ \\
\hline 5 & 100 & 11.0 & $25.6 \dagger$ & $11.9 *$ \\
\hline 10 & 170 & 11.2 & $30.7 \dagger$ & $15.2 \dagger$ \\
\hline 20 & 310 & 10.3 & $30.3 \dagger$ & 29.6 \\
\hline 60 & 870 & 10.1 & $22.0^{*}$ & - \\
\hline
\end{tabular}

Note-Comparisons with values to left: ${ }^{*} p<.05,+p<.025$. drinking opportunity. Indeed, it required a continuous drinking period of $310 \mathrm{~min}$ to produce approximately the same intake as occurred in only $30 \mathrm{~min}$ of access to the tube, when that $\mathbf{3 0}$ min was spaced out over the same total time. Because drinking after $310 \mathrm{~min}$ had already exceeded that of the 60-min interruption condition, the continuous-access drinking session was terminated at that point. Overall, the results show that the heightened drinking in the interruption sessions was not attributable simply to the greater total time that the drinking tube was available.

Drinking usually was depressed on the first uninterrupted control day after each interruption test session. Paired-measure $t$ tests comparing the day after and the 3rd day after an interruption session produced the following (two-tailed) $p$ values for the effects shown in Figure 4: $.1, .1, .05, .05$, and 1 , respectively. This depression might reflect the aftereffects of a mild malaise, for some of the rats drank more than $50 \mathrm{ml}$ on the interruption days and were noticeably inactive for up to $1 \mathrm{~h}$ after the drinking session.

Nonmonotonic functions frequently suggest the presence of two or more processes having different temporal characteristics. Solomon and Corbit's (1974) model of motivation assumes that one process is initiated by the stimulus (in this case, taste of saccharin solution) and decays rapidly when the stimulus is removed. A second process is assumed to be initiated by the first, to have an opposite hedonic value, and to show a slow rise and a relatively long decay time. The algebraic sum of the two hedonic states associated with these processes determines momentary motivation. In the present case, net motivation to drink saccharin was at a peak when 10-min interruptions separated 2-min drinks. The model could account for these results by assuming that the second process reaches its maximum strength approximately $12 \mathrm{~min}$ after the start of each bout of drinking, thus creating maximal craving just before each reintroduction of the drinking tube.

The second process in Solomon and Corbit's model (in this case, the process responsible for a negative hedonic state underlying the saccharin craving) is assumed to grow with use and decay with disuse. In these experiments, interrupted drinking should provide maximal use (15 initiations of the process per session), whereas the continuous drinking session should provide minimal use (1 initiation per session). Drinking should therefore increase to its maximum level with consecutive interrupted drinking days. However, placing uninterrupted drinking days between interrupted drinking days should allow the second process to weaken and thus result in less drinking. Experiment 5 evaluated these assumptions by presenting successive sessions of interrupted drinking to see if consumption increased across days and reached higher levels than those observed when interrupted drinking days were spaced among continuous-drinking baseline days. 


\section{EXPERIMENT 5 CONSECUTIVE INTERRUPTED DRINKING SESSIONS}

Drinking of saccharin solution is increased considerably when the opportunity to drink is broken into relatively brief periods. In the previous experiments, to avoid potential physiological stress consequent upon continued high-volume drinking, we had always separated the interrupted drinking sessions by uninterrupted (baseline) drinking days. The consequence of daily presentation of interrupted drinking opportunities is, however, of some interest. If the interrupted drinking effect is attributable to frustration-produced drive, consecutive daily sessions might be expected to diminish the intensity of the effect (Amsel \& Ward, 1965) as the anticipatory frustration response interferes increasingly with drinking. Frustration theory thus might predict that consecutive interrupted sessions would produce drinking that declines in volume on each successive day and approaches baseline levels. However, if the interrupted drinking effect is attributable to a hedonically aversive state created by prior experience with saccharin (Solomon \& Corbit, 1974), consecutive interrupted drinking sessions should do nothing to weaken, and probably should strengthen, that state (Solomon, 1982). Levels of drinking, therefore, should remain stable or even increase across consecutive sessions.

\section{Method}

Twenty-six rats without previous saccharin experience were given 16 consecutive uninterrupted drinking sessions of $30 \mathrm{~min}$ daily, using the .01-M concentration. Half the animals then were randomly assigned to be switched to $.0025-\mathrm{M}$ saccharin solution. After 10 days at these concentrations, the interruption procedure was introduced.
Drinking tubes were automatically inserted into test cages for 15 2-min drinking opportunities, separated by 4 -min withdrawal periods. There were 8 consecutive daily interrupted drinking sessions, and then two cycles, each consisting of 3 uninterrupted baseline days and an internupted drinking session. To avoid very high drinking levels that might depress drinking on the following day (cf. Experiment 4), the larger cages of Experiment 3 were again used. Food and water were available as in previous experiments.

\section{Results and Discussion}

Typical acquisition curves for taste-induced drinking again were observed, with asymptotic levels being approached over the first 7 days and, following the shift, the high- and low-concentration groups stabilizing about different levels. The 1st interruption day produced an increase in drinking for every animal (Figure 5). For both groups, the average change was an increase of approximately $38 \%$. On successive interruption days, although average consumption remained above baseline levels, intakes were below those of the 1st interruption day; there was no evidence, in the averages or in the drinking patterns of any individual, of an increase in saccharin drinking during the block of 8 consecutive interruption days, as might be expected on the basis of opponent process theory.

When blocks of 3 uninterrupted baseline days preceded an interrupted drinking session, statistically significant increases above the previous (baseline) day's intake levels were observed for both concentration groups, on both of the interruption tests ( $t$ for paired measures, one-tailed, all $p$ values $=.01$ or less, $d f=12$ ). The absolute levels of drinking on these spaced interrupted days were only trivially higher than those of the very first interrupted drinking test, demonstrating that level of intake does not

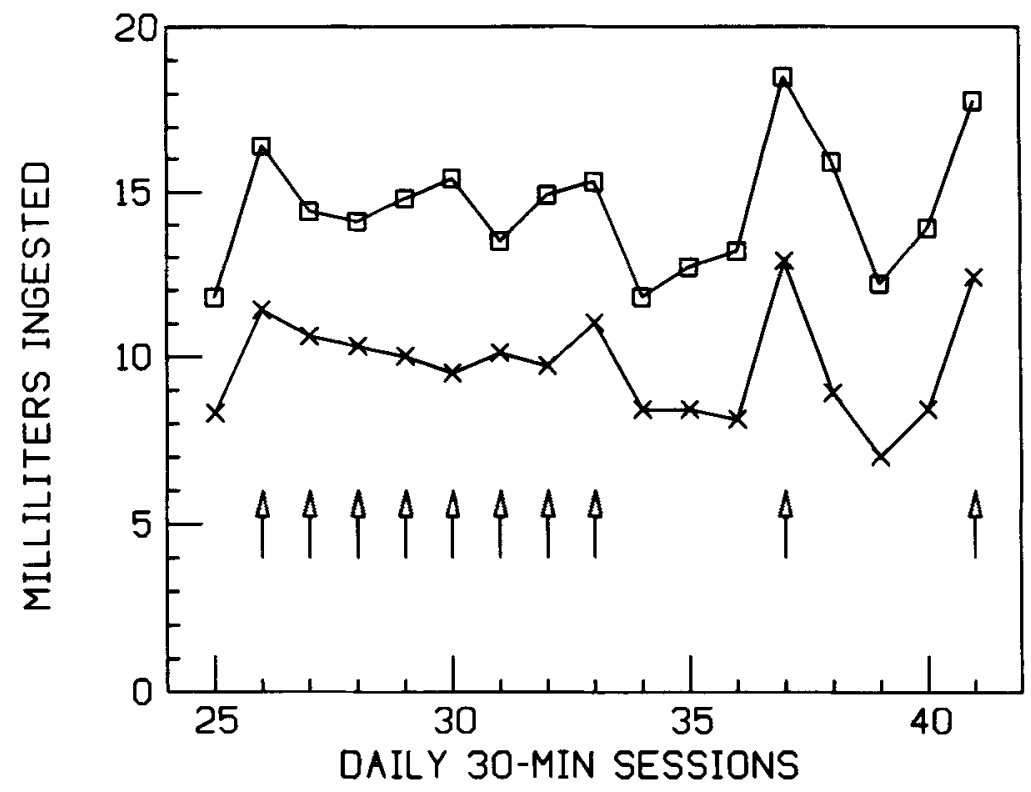

Figure 5. Effects of successive interrupted drinking sessions on mean intake. Arrows indicate interrupted drinking sessions. Continuous lines: unchanged concentrations. Broken lines: changed concentration. Squares: .01 M. Xs: .0025 M. 
change with further familiarity with the interrupted drinking procedure.

The block of 8 consecutive interrupted drinking sessions showed neither a reliable rise nor a decline in drinking. Volume ingested declined upon reintroduction of uninterrupted (baseline) drinking sessions, and rose again when the interrupted drinking procedure was again imposed. These results suggest that interrupted drinking has its effects within the context of the individual session, as contrasted with the more persisting effects that might be expected if vigorous drinking became conditioned to apparatus or procedural cues. The results also demonstrate again that a single concentration shift produces a persisting change in level of drinking that, in turn, is modulated by interruption of drinking.

\section{GENERAL DISCUSSION}

Two aspects of the results deserve further comment: the persisting positive and negative contrast effects, and the large increases in drinking when the drinking opportunities are broken into discrete periods.

The permanent shifts to new levels of drinking following a single shift in saccharin concentration are convincing evidence that TID cannot be adequately conceptualized as an index of sensory factors alone (cf. discussion in Jacobs \& Sharma, 1969). If palatability of substances is to be evaluated by observing drinking in nondeprived animals, strict control over their prior taste histories is essential.

The persistence of the contrast effects for the 4 weeks during which we followed them, and the presence of both positive and negative contrasts, distinguish these results from the bulk of the data on incentive contrasts and consummatory contrasts (see the important review by Flaherty, 1982). In most cases, contrast effects wane with repeated testing, and positive contrasts are especially ephemeral. Our results seem to be evidence against many of the prominent explanations of such contrasts that have been offered in the past. For example, the persistence of the effects would seem to eliminate hypotheses that invoke transient processes such as neophobia (Flaherty, Lombardi, Wrightson, \& Deptula, 1980) or elation and depression (Crespi, 1944), and explanations that appeal to gradually developing differences between groups in level of deprivation (Dunham \& Kilps, 1969) seem inappropriate when rats have been maintained on ad-lib food and water and have had comparable body weights throughout the experiments.

We would like to suggest that the unusually persistent contrast effects may be the result of the peculiar history of these animals. Although evolutionary processes have produced an organism with the peripheral and central mechanisms for detecting and reacting positively to most "sweet" substances (i.e., substances we label as such, and which are approached and consumed with avidity by rats), those structures and processes have never been fully activated in these animals prior to the first day of these experiments. In infancy, the milk of the mother probably excites no characteristic sweet reaction: rat milk is very low in lactose (approximately 3\%) and, to the human observer, it tastes "quite salty" (Luckey, Mende, \& Pleasants, 1954). To mature rats, 3\% lactose solutions are neither preferred nor rejected (Richter \& Campbell, 1940). The standard laboratory diet fed after weaning (Charles River RMH 3000) contains no ingredients that could directly produce a sweet taste for the rat. Thus, up to the first experimental day, the animals never received stimulation capable of producing a prototypical sweet reaction. On the first saccharin day, rats given the higher concentration probably had higher levels of peripheral and central gustatory activity than those drinking the lower concentration (review in Pfaffman et al., 1979), but since these were the only signals of that distinctive type that the brain had ever received, approach and drinking occurred with equal vigor for both concentration groups. Such nondifferential responding seems to be widespread in the absence of differential experience, having been documented in such diverse situations as stimulus generalization (Jenkins \& Harrison, 1960), conditioned stimulus effects in classical conditioning (Grice \& Hunter, 1964), and a large number of amount-of-reward studies (review in Kling \& Schrier, 1971).

A single shift in saccharin concentrations given to some animals produces a substantial between-groups difference in behavior in the absence of a between-groups difference in peripheral gustatory activity. For example, those rats drinking the .01-M saccharin solution from the beginning presumably have the same peripheral sensory activity as those rats switched to a .01-M from a .0025-M solution. Thus, the important difference between groups must be in the central processing of these sensory signals. The shifted animals, having had experience with two levels of gustatory input, may be considered to have developed a scale in memory representing the sweetness defined by two points, and two points only. A scale of this type, we suggest, is relatively free of interference effects in memory, whereas the central scale that would be generated, for example, in an amount-of-food experiment (1) would reflect a lifetime of prior experience with the food dimension, and (2) would continually be subjected to the interference of daily feedings. Thus, in contrast to the suggestion by Hulse (1973) that repeated and extensive experiences with the stimulus dimension (e.g., amount of food in his experiment) is a prerequisite to reliable contrast effects, our suggestion is that successive contrasts will be largest and most persisting when only one, and then only one other, value of the stimulus dimension is represented in memory. If our successive contrast effects are correctly conceptualized as a memory-dependent, subjective-scaling process, then experience with other concentrations prior to the shift should diminish the size of the contrast, because proactive interference would make it difficult to remember where on the scale of subjective goodness the pre- and the postshift solutions fall. By the same reasoning, experiences with other concentrations af- 
ter the shift should (through retroactive interference) diminish the persistence of the contrast. The first prediction is supported by the results of Flaherty, Becker, and Osborn (1983). An experimental test of the second hypothesis seems not to have been published, but the test would be straightforward.

The increase in TID when the drinking interval was interrupted would be predicted by Solomon and Corbit's (1974) model, which would expect the affectively negative saccharin craving to persist following withdrawal of the drinking tube and the affectively positive saccharin taste reaction to decrease very rapidly during the interval of nondrinking. The observation that total intake did not increase with further use (i.e., successive daily sessions) of the interruption method (Experiment 5) is inconsistent with the model's assumption that the negative state should grow with repeated elicitation.

Enhanced consumption of ethanol solutions under discontinuous drinking conditions has been reported on several occasions. For example, Marcucella and his colleagues (e.g., Marcucella, Munro, \& MacDonall, 1984) showed that rats consume more ethanol per bout of drinking when the daily drinking opportunity is broken into restricted (e.g., $20 \mathrm{~min}$ ) periods than when unrestricted drinking is permitted. Because this effect occurs only when the rats are food deprived, it was suggested that the results reflect an attempt by the animals to maintain caloric balance (Marcucella \& Munro, 1986). However, Pinel and Huang (1976) demonstrated similar patterns of increased preference and increased intake when ethanol and when saccharin solutions were presented every second day, indicating that caloric regulation is not always involved. In both experiments by Marcucella and his colleagues, and in that of Pinel \& Huang, the enhanced intake developed slowly, over the course of 20-30 days. In contrast, our interrupted drinking effect appears essentially instantaneously. There thus seems to be a fundamental difference between the distributed drinking effect found in the ethanol experiments and the interrupted drinking effect we have observed.

There may be some value in noting the similarities between this interrupted drinking procedure and the scheduled feeding procedures that produce adjunctive behaviors. Although our rats were not deprived of food or water, after the first few saccharin exposures, they behaved as if they were very strongly motivated to drink saccharin: they tried to hold the tubes with teeth and paws as the tubes were withdrawn; during periods of tube withdrawal, they engaged in such "displacement" activities as gnawing on the wire cage floor and around the tube aperture; and most animals showed occasional, unpredictable, explosive jumps from the floor against the cage lid. These behaviors may suggest the presence of a high state of arousal resulting from confinement in the presence of the cues for drinking saccharin. Such conditions seem to be the common situations in which "schedule-induced adjunctive behavior" appears (Falk, 1977). A concomitant of such situations is a high level of pituitary-adrenal ac- tivity that is quickly reduced when the adjunctive response (e.g., drinking) occurs (Brett \& Levine, 1979). In our situation, the highly motivated response constrained by an externally imposed schedule and the species-typical response that can reduce the corticosterone level happen to be the same. The results suggest that the level of arousal rises for at least 10 min after the tube is withdrawn, whereas in fixed-time food-reinforcement experiments, the bitonic function reflecting arousal level usually has its peak in the vicinity of 2 min (Falk, 1977). There are numerous procedural differences that might account for this apparent discrepancy. Further investigation of short intervals in our drinking situation seems necessary.

The vigor and the persistence of the TID, and the rats' striving to continue the drinking when forced interruptions occurred, suggest that very strong craving for the saccharin solutions had developed. Perhaps these procedures will offer a laboratory model for study of the taste addictions that are developing in the U.S. (and, possibly, elsewhere). An appreciation of the intensity of the craving for soft drinks that has been developed by some persons can be obtained from the reports that the per capita average (mean) yearly consumption now approximates $38 \mathrm{gal}$ (144 liters) (Bureau of the Census, 1986, p. 121, Table 196), and that the primary consuming age groups, in the last year for which such data were available, were averaging over 100 gal (378 liters) in yearly intake (U.S. Department of Agriculture, 1980).

\section{REFERENCES}

AMSEL, A. (1958). The role of frustrative nonreward in noncontinuous reward situations. Psychological Bulletin, 55, 102-119.

Amsel, A., Roussel, J. (1952). Motivational properties of frustration: I. Effect on a running response of the addition of frustration to the motivational complex. Journal of Experimental Psychology, 43, 363-368.

AMSEL, A., WARD, J. S. (1965). Frustration and persistence: Resistance to discrimination following prior experience with the discriminanda. Psychological Monographs, 79(Whole No. 597).

Barker, L. M., Best, M. R., Domjan, M. (Eds.). (1977). Leaming mechanisms in food selection. Waco, TX: Baylor University Press.

BARNETT, S. A. (1963). The rat: A study in behaviour. Chicago: Aldine.

BEST, M. R., \& BARKER, L. M. (1977). The nature of "learned safety" and its role in the delay of reinforcement gradient. In $L$. M. Barker, M. R. Best, \& M. Domjan (Eds.), Leaming mechanisms in food selection (pp. 295-317). Waco, TX: Baylor University Press.

Bevan, W. (1966). An adaptation-level interpretation of reinforcement. Perceptual \& Motor Skills, 23, 511-531.

Brett, L. P., \& Levine, S. (1979). Schedule-induced polydipsia suppresses pituitary-adrenal activity in rats. Journal of Comparative \& Physiological Psychology, 93, 946-956.

Bureau of the Census, U. S. Department of Commerce. (1986). Statistical Abstract of the United States, 1985 (105th ed.). Washington, DC.

Cabanac, M. (1971). Physiological role of pleasure. Science, 173, 1103-1107.

Crespi, L. (1944). Amount of reinforcement and level of performance. Psychological Review, 57, 341-357.

DAvis, J. D., \&eVINE, M. W. (1977). A model for the control of ingestion. Psychological Review, 84, 379-412.

Dunham, P. J., \& KıLPs, B. (1969). Shifts in magnitude of reinforcement: Confounded factors or contrast effects? Joumal of Experimental Psychology, 79, 373-374. 
Ernits, T., Corbit, J. D. (1973). Taste as a dipsogenic stimulus. Joumal of Comparative \& Physiological Psychology, 83, 27-31.

FALK, J. L. (1977). The origin and functions of adjunctive behavior. Animal Leaming \& Behavior, 5, 325-335.

Flaherty, C. F. (1982). Incentive contrast: A review of behavioral changes following shifts in reward. Animal Leaming \& Behavior, 10, 409-440.

Flaherty, C. F., Becker, H. C., \& Osborn, M. (1983). Negative contrast following regularly increasing concentrations of sucrose solutions: Rising expectations or incentive averaging? Psychological Record, 33, 415-420.

Flaherty, C. F. \& KAPLAN, P. S. (1979). Gustatory contrast in rats. Chemical Senses \& Flavour, 4, 63-72.

Flaherty, C. F., Lombard, B. R., Wrightson, J., \& Deptula, D (1980). Conditions under which chlordiazepoxide influences successive gustatory contrast. Psychopharmacology, 67, 269-277.

Flaherty, C. F., Rowan, G. A. (1986). Successive, simultaneous, and anticipatory contrast in the consumption of saccharin solutions. Journal of Experimental Psychology: Animal Behavior Processes, 12 , 381-393.

Gandelman, R., Trowill, J. A. (1969). Effects of reinforcement shifts upon subsequent saccharin consumption. Psychonomic Science, $15,25$.

Grice, G. R., Hunter, J. J.(1964). Stimulus intensity effects depend upon the type of experimental design. Psychological Review, 71, 247-256.

Helson, H. (1966). Some problems in motivation from the point of view of the theory of adaptation level. In D. Levine (Ed.), Nebraska Symposium on Motivation (pp. 137-182). Lincoln: University of Nebraska Press.

HULSE, S. H. (1973). Reinforcement contrast effects in rats following experimental definition of a dimension of reinforcement magnitude. Journal of Comparative \& Physiological Psychology, 85, 160-170.

Jacoes, H. L., Sharma, K. N. (1969). Taste versus calories: Sensory and metabolic signals in the regulation of food intake. Annals of the New York Academy of Sciences, 157, 1084-1125.

Jarvik, M. E., Popek, P., Schneider, N. G., Bafer-Weiss, V., \& GrITZ, E. R. (1978). Can cigarette size and nicotine content influence smoking and puffing rates? Psychopharmacology, 58, 303-306.

JENKINS, H. M., HARRISON, R. H. (1960). Effect of discrimination training on auditory generalization. Journal of Experimental Psychology, 59, 246-253.

KALAT, J. W. (1977). Status of "learned safety" or "learned noncorrelation" as a mechanism in taste aversion learning. In $L$. M. Barker, M. R. Best, \& M. Domjan (Eds.), Learning mechanisms in food selection (pp. 273-293). Waco, TX: Baylor University Press.

Kling, J. W., Schrier, A. M. (1971). Positive reinforcement. In J. W. Kling \& L. A. Riggs (Eds.), Experimental psychology (3rd ed., pp. 615-702). New York: Holt, Rinehart \& Winston

Luckey, T. D., Mende, T. J., \& Pleasants, J. (1954). The physical and chemical characterization of rat's milk. Joumal of Nutrition, 54, 345-359.

MacKinnon, J. R., AMSEL, A. (1964). Magnitude of the frustration effect as a function of confinement and detention in the frustrating situation. Joumal of Experimental Psychology, 67, 468-474.

MACKINTOSH, N. J. (1974). The psychology of animal leaming. London: Academic Press.

Marcucella, H., Munro, I. (1986). Patterns of ethanol and water consumption as a function of restricted ethanol access and feeding condition. Pharmacology, 89, 145-149.

Marcucella, H., Munro, I., \& MacDonall, J. S. (1984). Patterns of ethanol consumption as a function of the schedule of ethanol availability. Journal of Pharmacology \& Experimental Therapeutics, 230, 658-664.

MARX, M. H., \& PiePER, W. A. (1962). Acquisition of instrumental response as a function of incentive contrast. Psychological Reports, 10, 635-638.

McMorrow, M. J., Foxx, R. M. (1983). Nicotine's role in smoking: An analysis of nicotine regulation. Psychological Bulletin, 93, 302-327.

Pfaffmann, C. (1960). The pleasures of sensation. Psychological Review, 67, 253-268.

Pfaffmann, C., Frank, M., \& Norgren, R. (1979). Neural mechanisms and behavioral aspects of taste. Annual Review of Psychology, 30, 283-325.

Pinel, J. P. J., \& Huang, E. (1976). Effects of periodic withdrawal on ethanol and saccharin selection in rats. Physiology \& Behavior, 16, 693-698.

Pinel, J. P. J., RovNer, L. I. (1977). Saccharin elation effect. Bulletin of the Psychonomic Society, 9, 275-278.

Revusky, S. H. (1967). Hunger level during food consumption: Effects on subsequent preference. Psychonomic Science, 7, 109-110.

Richter, C. P., CAMPBELL, K. H. (1940). Taste thresholds and taste preferences of rats for five common sugars. Journal of Nutrition, 20 , $31-46$.

Riley, E. P., DunLAP, W. P. (1979). Successive negative contrast as a function of deprivation condition following shifts in sucrose concentration. American Journal of Psychology, 92, 59-70.

Rolss, B. J., Wood, R. J., Rolss, E. T. (1980). Thirst: The initiation, maintenance, and termination of drinking. In J. M. Sprague \& A. N. Epstein (Eds.), Progress in psychobiology and physiological psychology (Vol. 9, pp. 263-321). New York: Academic Press.

Rolls, B. J., Wood, R. J., SteVENS, R. M. (1978). Effects of palatability on body fluid homeostasis. Physiology \& Behavior, 20, 15-19.

SCHRIER, A. M. (1958). Comparison of two methods of investigating the effect of amount of reward on performance. Joumal of Comparative \& Physiological Psychology, 51, 725-731.

SIEGEL, S. (1979). The role of conditioning in drug tolerance and addiction. In J. D. Keehn (Ed.), Psychopathology in animals: Research and clinical implications. New York: Academic Press.

Solomon, R. L. (1982). The opponent processes in acquired motivation. In D. W. Pfaff (Ed.), The physiological mechanisms of motivation (pp. 321-336). New York: Springer-Verlag.

Solomon, R. L., \& CoRBrt, J. D. (1974). An opponent-process theory of motivation: I. Temporal dynamics of affect. Psychological Review, 81, 119-145.

SpeCtor, A. C., \&Mith, J. C. (1984). A detailed analysis of sucrose drinking in the rat. Physiology \& Behavior, 33, 127-136.

STELlar, E. (1977). Sweet preference and hedonic experience. In J. M. Weiffenbach (Ed.), Taste and development: The genesis of sweet preference (Report No. NIH 77-1068). Bethesda, MD: Department of Health, Education \& Welfare.

U.S. DePartment of AGriculture. (1980). Food consumption, prices, and expenditures, 1960-1980 (Statistical Bulletin No. 672). Washington, DC: U.S. Department of Agriculture, National Economics Division, Economic Research Service.

Vogel, J. R., MikulKa, P. J., \& SPEAR, N. E. (1968). Effects of shifts in sucrose and saccharin concentrations on licking behavior in the rat. Journal of Comparative \& Physiological Psychology, 66, 661-666.

WEINSTEIN, L. (1970). Negative incentive contrast with saccharin versus sucrose and partial reinforcement. Psychonomic Science, 21, 276-278.

WeINSTEIN, L. (1978). Negative and positive incentive contrast effects with saccharin versus sucrose. Joumal of General Psychology, 98, 225-240.

Young, P. T. (1967). Palatability: The hedonic response to foodstuffs. In C. F. Code (Ed.), Handbook of physiology (Vol. 1, section 6, pages 353-366). Washington, DC: American Physiological Society.

(Manuscript received May 5, 1987; revision accepted for publication March 11, 1988.) 